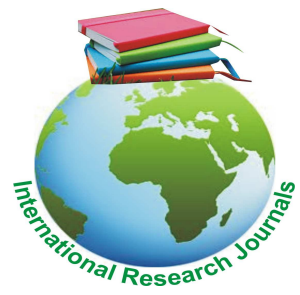

Journal of Medicine and Medical Sciences Vol. 8(5) pp. 060-068, August 2017

DOI: http:/dx.doi.org/10.14303/jmms.2017.0117

Available online http://www.interesjournals.org/JMMS

Copyright (c) 2017 International Research Journals

Full Length Research

\title{
Pattern of wounds in Bingham University Teaching Hospital, Jos
}

\author{
Modupe I Builders ${ }^{1^{*}}$, Edwin Oseni-Momodu ${ }^{2}$ \\ ${ }^{1}$ Department of Pharmacology and Therapeutics, College of Health Sciences, ${ }^{2}$ Department of Surgery, \\ College of Health Sciences, Bingham University, Jos, Nigeria \\ Corresponding author's e-mail: modupebuilders@yahoo.com
}

\begin{abstract}
Wound represents a major health burden in Africa and most parts of the world. In this study, woundrelated visits and hospitalization in a teaching hospital in Northern Nigeria were documented; this involved a retrospective on-site medical record review of wound-related hospital admissions from 1st April 2014 through 31st June 2014. Out of 139 patients that visited the hospital for wound-related cases, $63.4 \%$ were males, month of June had the highest admission (43.9\%), and the age group 21-30 years formed the largest proportion (38.9\%). The leading cause of wound was incision $(54.0 \%)$, followed by avulsion (33.1\%), analgesics were the most prescribed drugs $(34.2 \%)$, antibiotics ranked the second prescribed drugs $(32.9 \%)$, pentazocine was the most analgesic commonly administered $(33.0 \%)$ and $60.3 \%$ of the patients that visited the hospital for wound-related cases stayed up to 7 days. There were significant association between the gender of the patients and causes of wounds, drugs prescribed, types of analgesics prescribed as well as a significant association between causes of wounds and length of stay at 0.01 level (2-tailed). This study provides considerable information on major causes of wounds and will be useful for planning program of education and health care policy.
\end{abstract}

Keywords: Wounds, Pattern, Patients, Health care providers.

\section{INTRODUCTION}

Wounds constitute among the major causes of visits to hospitals in Africa, accounting for about 30-42\% of hospital attendance and $9 \%$ death every year (Adigun et al., 2015; Norman et al., 2006). It is also among the most underreported health challenges in many parts of Africa, probably because of the poor access to hospitals among other reasons (Builders and Builders, 2016). Wound is a circumscribed damage resulting in disruption of the continuity of the epithelial lining of the skin or other tissues in which integrity and/or protective functions of the tissue is compromised, wounds may be caused by physical, chemical, disease, or combinations of these factors (Kumarasamyrajaet al., 2012) and can be broadly classified as acute or chronic. Acute wounds usually heal in an ordered, timely fashion, and are typically seen as post-operative wounds, minor lacerations, abrasions, minor burns and scalds and some trauma wounds (Adigun et al., 2015; Norman et al., 2006). Conversely, chronic wounds do not follow this ordered sequence of events and are characterized by delayed healing, cellular senescence, and recurrent infections (Norman et al., 2006). The healing of wound can be enhanced or impeded by local and systemic factors. The local factors include infections, slough and necrotic tissues, low 
oxygen tension, inadequate perfusion, foreign bodies, poor wound hygiene, and pressure, while the systemic factors include cardiovascular disorders, nephropathy, metabolic disorders (diabetes), high age, medication (e.g., steroidal anti-inflammatory drugs), poor nutrition, smoking, and immune suppression, under favourable healing factors wounds will heal fast even with minimum intervention (Bodeker and Kronenberg, 2002).

Wounds not only impact on the individual and their quality of life, they also have a significant impact on our health service and our society as a whole. The primary source of interventions to wounds is the hospitals where health professionals are available to manage the different types of conditions as may be presented by the patients (Builders and Builders, 2016).

Information on the documentation of wound-related cases in our hospitals is scarce largely due to lack of data on the epidemiology of wounds. Data on wounds is essential to generate evidence based safety strategies and prevention efforts. Reliable research on wound burden and pattern will also help in organization and delivery of wound care. Thus, there is greater emphasis on the need to generate reliable and consistent information on the pattern and distribution of wounds so as to design effective prevention strategies (Lakshmiet al., 2016)

Therefore this study was conducted to examine the pattern of wounds in a health care setting and the objectives are to determine causes of wounds, pattern of medications prescribe, as well as length of stay for patients treated with wounds-related cases. This study is important as it will improve efforts at wounds treatment and prevention.

\section{METHOD}

\section{Study facility}

This study was carried out retrospectively at the medical record department of Bingham University Teaching Hospital (BHUTH), Jos, Plateau state. BHUTH is a missionary hospital in Northern region of Plateau state of Nigeria with a total capacity of 1000 beds; it is a major center for providing tertiary care for patients in the Northern province in Nigeria. The hospital is affiliated to College of Health Sciences, Bingham University, Jos campus. The study was approved by Health research and Ethics committee of the teaching hospital.

\section{Study population}

A total of 139 patients who visited the teaching hospital for wounds related cases from 1st April 2014 through 30th June 2014 were studied retrospectively. Patient data forms were used to collect information from the medical records; these included demographic characteristics, causes of wound, medication prescribed and date of admission and discharge. Excluded from the study were patients treated for non-wound related cases, less than one year, outpatients, discharge patients against medical advice and dead patients.

\section{Study limitation}

The limitation of this study included lack of prospective design, outpatients department due to limited resources, time constraints and its completeness and costs of wounds treatment.

\section{Statistical analysis}

Data were analyzed with Statistical Package for the Social Sciences version 20.0 software (SPSS Inc., Chicago, IL, USA). Descriptive statistics, including count and percentage, were used to describe the demographic characteristics of the patients and 2-tailed test of significance was done by bivariate analysis using Pearson correlation coefficient.

\section{RESULTS}

Figure 1 shows the sex distribution of the patients. $43.9 \%$ of the patients were treated for wounds in the month of June; this month had the highest admission of patients treated for wounds. Majority of these patients were males (63.3\%) and $36.7 \%$ were females with a male to female ratio of approximately $1.7: 1$. There was no significant association between the sex of the patient and month of admission of the patient.

Young adults aged 21-30yrs had the highest wounds related cases (38.9\%), followed by economically productive age group $31-50$ years (23.0\%), while teenagers comprised (18.0\%), older people aged 50yrs and above $(7.9 \%)$ had the least treated wound cases. There was no significant association between the sex of 
062 J. Med. Med. Sci.

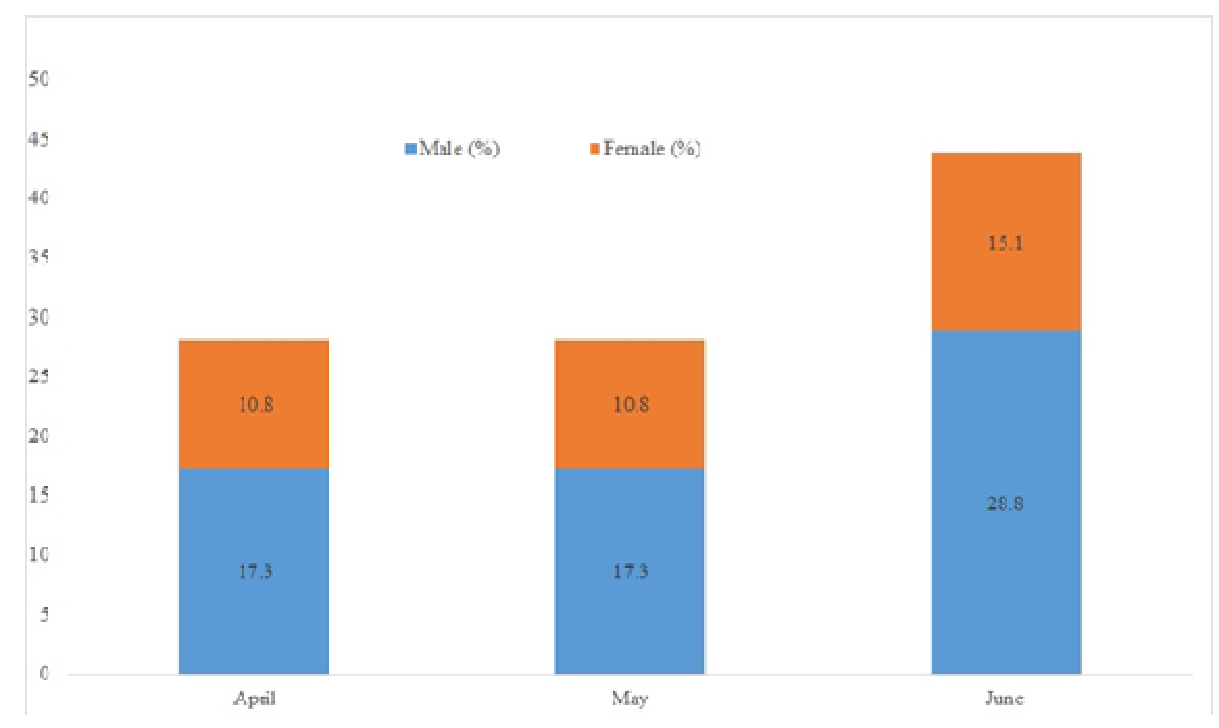

Figure 1: Sex distribution of the patients

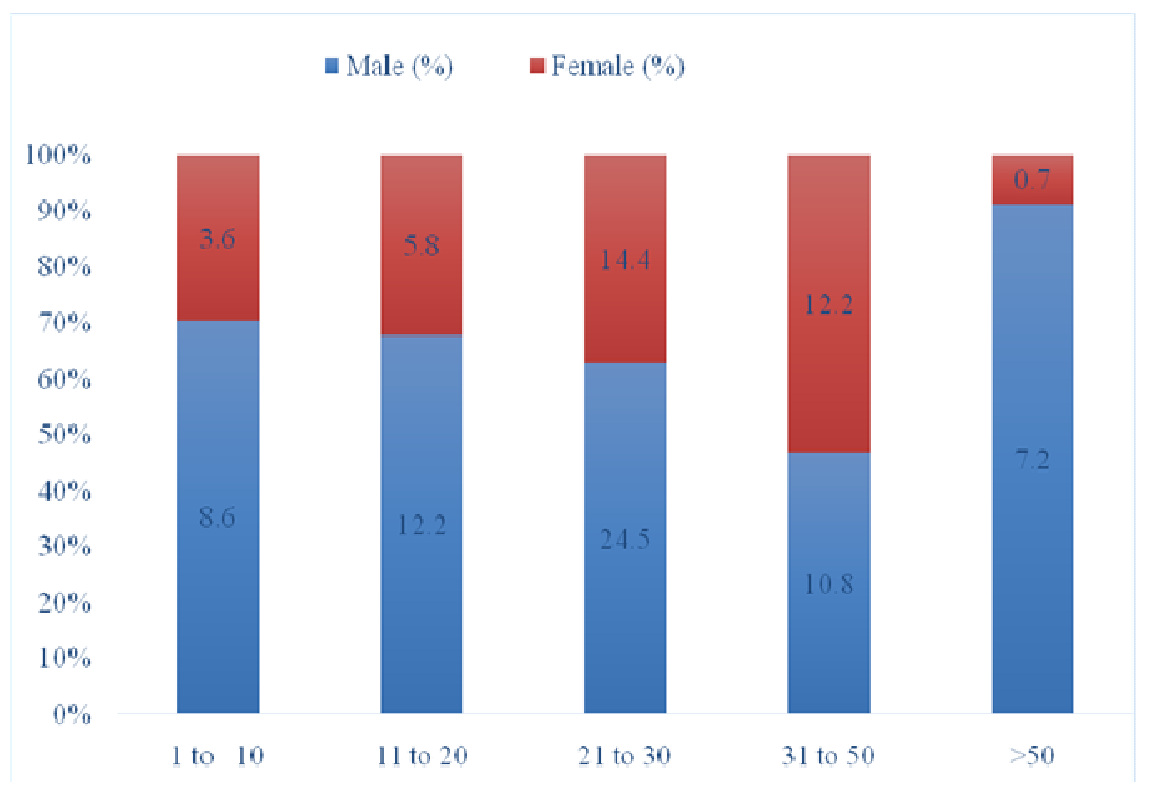

Figure 2. Age distribution of patients.

the patient and the age of the patient as indicated in figure 2 above.

Figure 3 below indicates the causes of wounds among the patients. Topmost on the list was incision
(54.0\%), followed by avulsion (33.1\%) while laceration had the least of patients (2.1\%). There was a significant association between the sex of the patient and the causes of wounds. 
Modupe and Edwin, 063

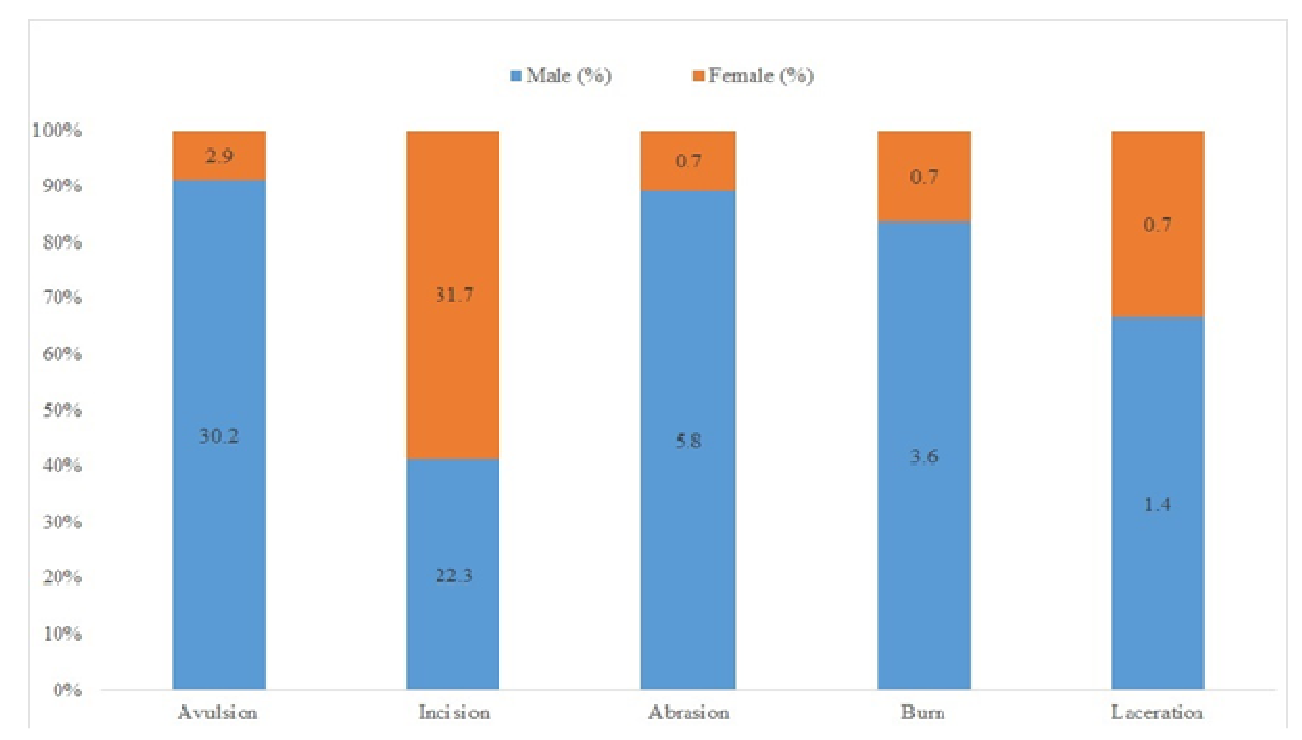

Figure 3. Causes of wounds.

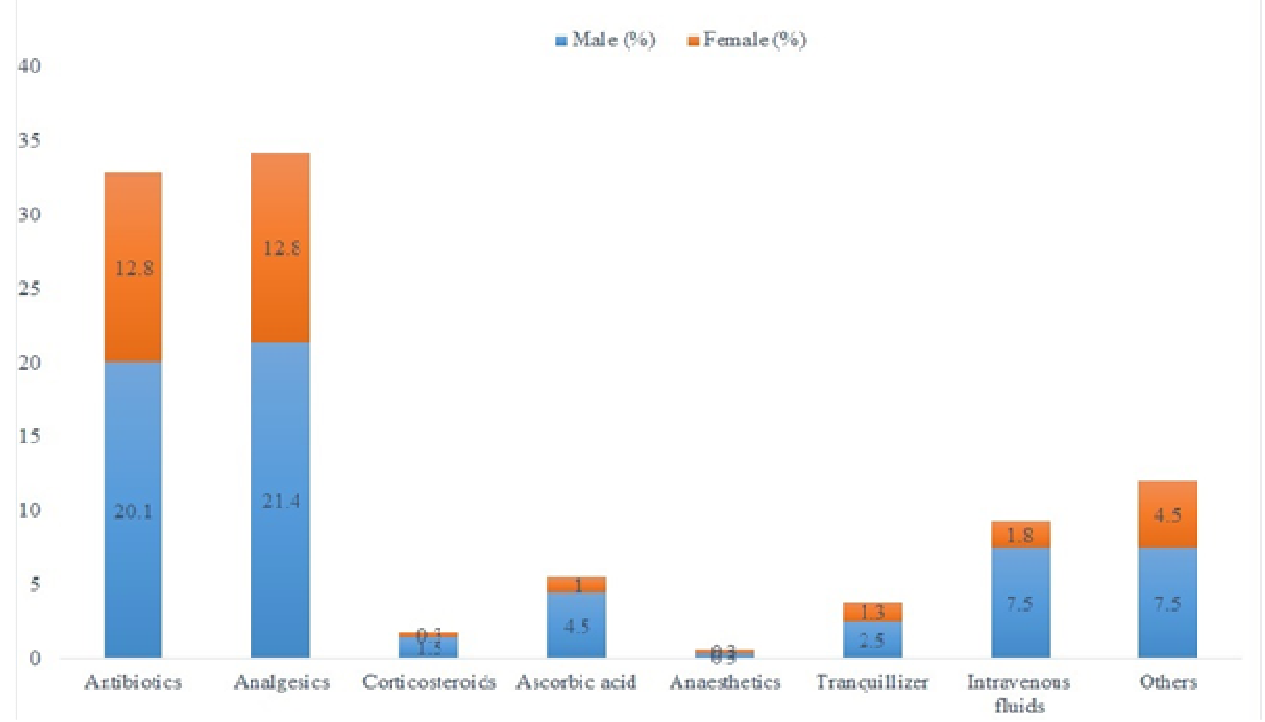

Figure 4. Drugs prescribed for the patients.

The top three leading drugs prescribed for wounds were analgesics $(34.2 \%)$, antibiotics $(32.9 \%)$ and other medications $(12.0 \%)$ while anaesthetics $(0.6 \%)$ had the least prescriptions. There was a significant association between the sex of the patient and drug prescription as illustrated in figure 4 above.
The most prescribed analgesic was pentazocine $(33.0 \%)$, ibuprofen $(24.8 \%)$ ranked second while morphine $(1.0 \%)$ had the least analgesic prescription. There was a significant association between analgesic prescription and sex of the patient as shown in figure 5 below. 
064 J. Med. Med. Sci.

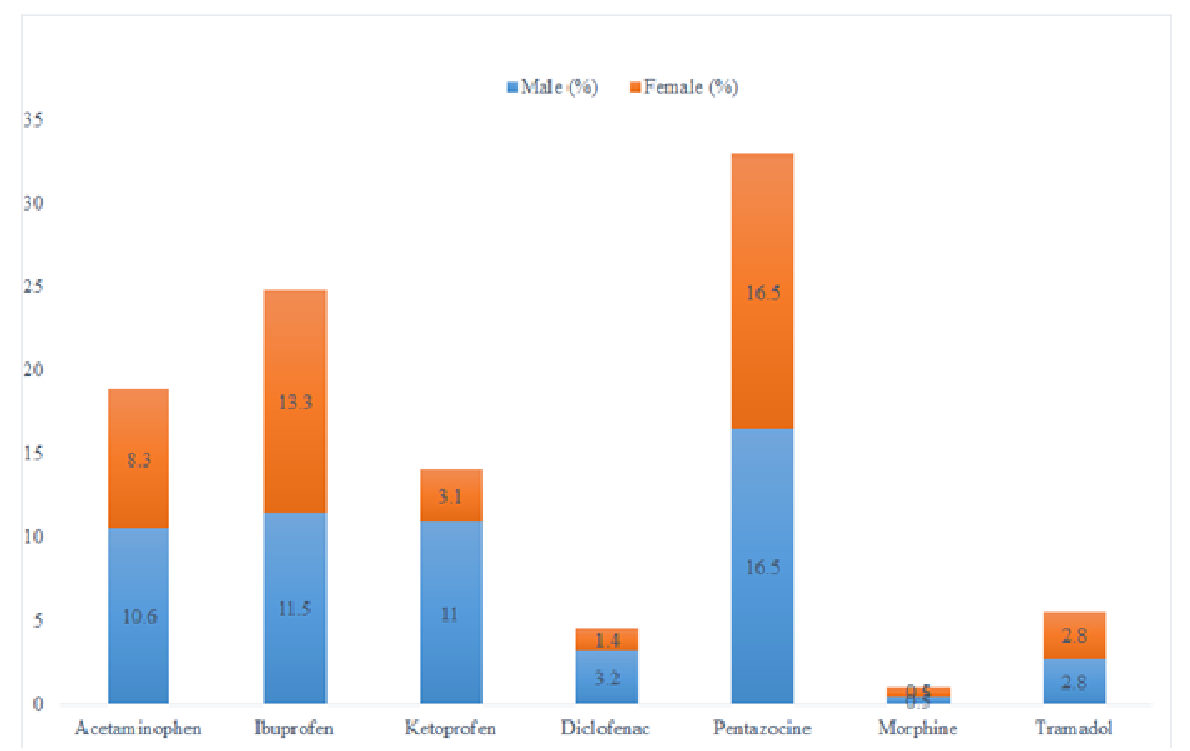

Figure 5. Analgesics prescribed for the patients.

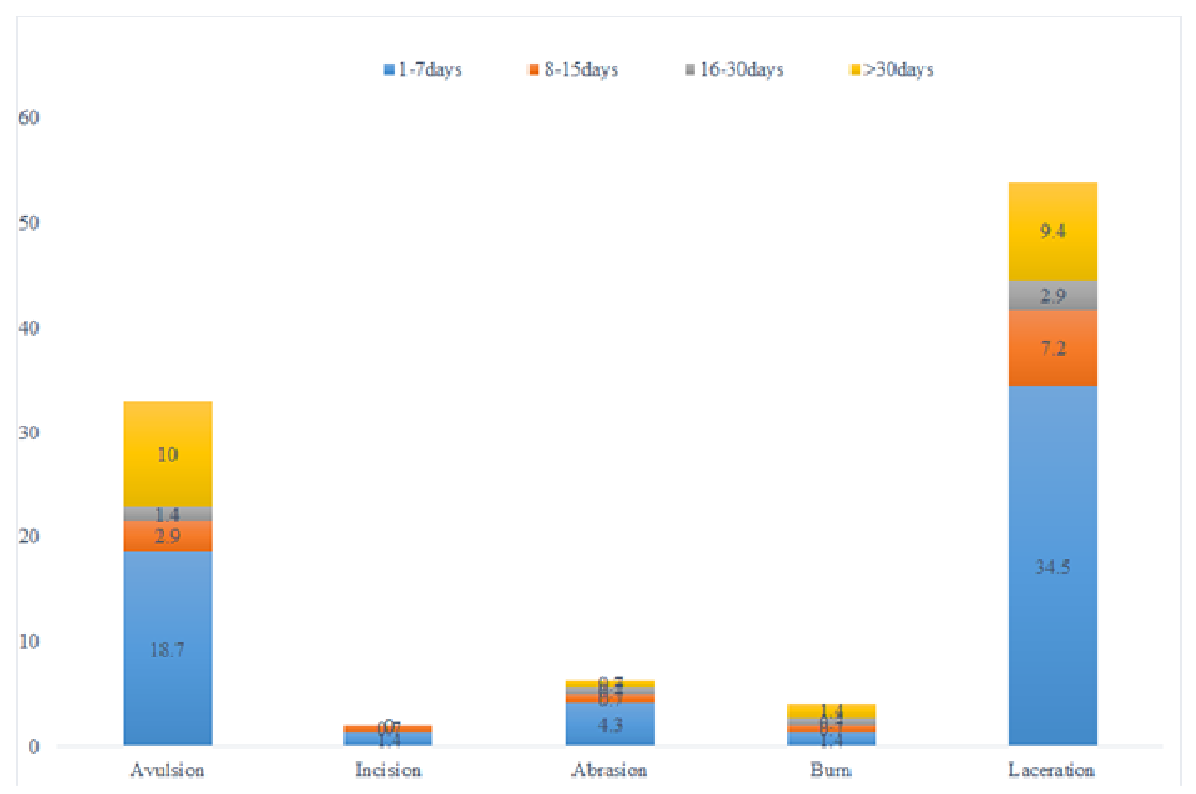

Figure 6. Relationship between causes of wounds and length of stay.

Figure 6 indicates the relationship between the causes of wound and length of stay. Majority of the patients admitted for wound related cases stayed up to 7 days $(60.3 \%)$ while $21.5 \%$ of the patients were on admission for more than 30 days. There was a significant association between the causes of wounds and length of stay. 


\section{DISCUSSION}

As a result of contemporary complex lifestyles that predisposes people to physical injuries and diseases that cause wounds, wounds will continue to be an important health challenge in Africa as well as other parts of the world (Builders and Builders, 2016). There was season variation of patients' admission from April to June. June had the maximum number of injuries, this might be probably due to slippery roads as a result of rains, and also research had shown that injuries peak during the summer months of June-August (Foltranet al., 2013; Morrisonet al., 1999)

Several studies had shown that the relationship between age and wound varied depending on the type of wound. For open wounds, the relationship was as expected, with the risk of injury starting out higher for younger workers then declining with age. Young people face a higher relative risk of open-wound injuries, such as scrapes, cuts, lacerations and burns, middle-aged patients face a higher relative risk for both traumatic and non-traumatic musculoskeletal injuries (sprains, strains, tendinitis, repetitive strain injuries, etc.), while Older people face a higher relative risk of trauma to bone and ligament injuries, such as fractures and dislocations (Smith , 2013) .

In this study, majority of wound patients were predominantly individuals in the economically active age group of 21-50 years with a peak at 21-30 years, depleting the economically productive population, which bears a direct impact on the productivity of individuals, families, communities and the country, similar to what were observed in some researches (Smith 2013; Cheng et al., 201514).

Investigators had indicated that age and seniority appear to be protective factors against wounds in their studies, perhaps because older, more senior workers within a job category may be protected from performing the more physically demanding tasks by the younger workers. So that; the more experienced workers are likely more familiar with the job tasks and therefore able to perform certain tasks more safely (Taiwoet al., 2009).

A higher incidence of wound was noted in males than females with a male to female ratio of $1.7: 1$, this is consistent with some studies in which highincidence of wounds in men are higher proportion of men in out ofhome works, using motor vehicles and wider participation in physical and social activities such as alcohol consumptions (Nick et al., 2013; Ameri et al., 2016; Onwuezobeet al., 2016).

Since the incidence of wounds across age groups did not change over time and young adult males account for the majority of wounds- related cases, therefore age and gender did not significantly affect wounds in this study. This is in agreement with other Nigerian studies,

Which indicated no significant difference in both sexes more observed in their studies as a result of prevalent wounds in male patients than in females probably due to the fact that males are involved more in accident prone occupation and social life (Smith, 2013; Oladeinde et al., 2013; Onwuezobe et al., 2016).

The historical and clinical features surrounding the cutaneous injury process differ, wounds must be evaluated and treated individually (Nick et al., 2013 ), as a result the causes of wounds differ from country to country and from hospital to hospital even within the same region (Oladeinde et al., 2013). The various wound types revealed by this study included assaults, road crashes, gunshots, bomb blasts, animal bites, burns, surgery, diseases, occupational, and domestic accidents resulting in acute or chronic soft tissue damage due to Avulsions, abrasions, incisions, burn and lacerations. These types of injuries might be due to the occupation and social life of the people in this Northern part of Nigeria. This pattern of causes of wounds in this health care setting is similar to other teaching hospitals in some African countries like Kenya, Ethiopia and Nigeria (Ogendi and Ayisi, 2011; Onwuezobe et al., 2016).

More than half of the young adult male patients were admitted for various wounds related cases similar to some other studies (Mohammedet al., 2013) and this might be attributed to the social behavior where males are given superiority to the females, and if contacted disease are brought immediately to hospitals in comparison to female for treatment (Builders et al., 2014; Mohammedet al., 2013). This also explains the significant association between the gender and causes of wounds in our study.

A number of measures including dressing and administration of painkillers, use of anti inflammatory agents, antimicrobial agents, and healing promoting drugs are involved in wound care and management (Thakuret al., 2015).

The therapeutic drug classes mentioned during wounds treatment were antimicrobials, analgesics, corticosteroids, ascorbic acid, anaesthetics, tranquillizer, intravenous fluids and miscellaneous. Since pain is an important feature of wounds and is an unpleasant sensation that is felt as a result of the brain's response to damage in thebody (Builders et al., 2011).

Pains due to wounds are usually localized, intense, and persistent, and may be exacerbated by physical and psychological factors can be classified as nociceptive and neuropathic pain (Builders and Builders, 2016). The top 
066 J. Med. Med. Sci.

most leading therapeutic agents administered for these patients were analgesics, including narcotic and nonnarcotic pain medications and nonsteroidal antiinflammatory drugs.

Infection is the major complication of wounds and antibacterial agents play an important role in the wound healing process and can delay the process by several mechanisms such as decreasing blood supply, promoting disordered leukocyte function, prolonging inflammatory and debridement phases and producing proteolytic enzymes (Eming et al., 2007). Therefore antibiotics ranked the second prescribing medication and it is now generally accepted that systemic antibiotics are essential for the management of clinically infected wounds, the choice of antibiotic to be used is not always apparent. Only after a comprehensive assessment process including consideration of patient characteristics, the results of microbiological investigations and the identification of both the nature and location of the wound, as well as the identification of most appropriate antibiotic (Collier, 2001; Mohammed et al., 2013).

Inflammation is a protective process conducted by the organism with the purpose of removing the harmful stimuli and initiating the operation of healing. However, the excessive and unbalanced inflammation could delay the healing period and enhance scarring which suggests a promising target for future therapeutic interventions or even predisposes tissue to cancer development (Eming et al, 2007). Therefore, anti-inflammatory compounds such as corticosteroids are considered as effective agents in wound healing (Chandran and Kuttan, 2008). Corticosteroids focus on the inhibition of prostaglandin synthesis and its administration has been shown to reduce inflammation, pain, and length of hospital stay in burn patients in several small studies (Rowan et al., 2015).

Antioxidants such as ascorbic acid could also have an important role in survival of ischemic skin flaps or promotion of wound healing (Eming et al., 2007) , as many preclinical studies have demonstrated promising reductions in necrosis with systemic antioxidant administration (Rowan et al., 2015) due to the role of oxidative stress in the development of necrosis. Vitamins C (L-ascorbic acid), shows potent anti-oxidant and antiinflammatory effects. Vitamin $\mathrm{C}$ deficiency has multiple effects on tissue repair resulting in impaired healing, and has been linked to decreased collagen synthesis and fibroblast proliferation, decreased angiogenesis, and increased capillary fragility. Also, vitamin C deficiency leads to an impaired immune response and increased susceptibility to wound infection (Guo and Dipietro, 2010).
Our findings also show that some of the patients sustained penetrating wounds including road trashes, trauma and burns that required quite several needed blood transfusion similar to research conducted in Kenya (Ogendi and Ayisi, 2011). Little is known about the effect of resuscitation fluid compositions and volumes on wound healing. Research have recently shown that the rate of wound closure (healing rate) is significantly faster in patients who received lower 24-h fluid resuscitation volumes. More work is needed to evaluate the effect of resuscitation on wound healing trajectories before clinical recommendations for preferred fluid compositions and volumes can be made (Rowan et al., 2015).

In addition, many wound patients are already at high risk factors such as immobility and dehydration (Pediani, 2001), as a result of volume loss from hemorrhage, wounds involving more than $10 \%$ of the body surface area are associated with loss of excess extracellular fluid, may become life-threatening, and often need inpatient management (Nick et al., 2010).

Proper wound evaluation and cleansing can be a painful process that may cause less physical and emotional damage if anesthetics are used. Current options include topical, local injection, and regional anesthetics (Nick et al., 2010), therefore some of the wound patients were administered anaesthetics.

There are many psychological and emotional factors associated with living with a wound that can affect patients' perception of pain, such as anxiety, stress, fear and depression (Brown, 2014). Living with chronic wound pain, particularly when wound malodour or high exudate levels are present, can result in reduced self-belief, isolation and loss of identity; many patients also experience sleep disturbance, which further reduces their pain tolerance (Brown, 2014). Also, another component of affective distress that is relevant to pain is depression. Many studies have demonstrated that depression and pain are highly co-morbid, (Fillingimet al., 2009), therefore anxiolytics made the list of prescription for wound patients.

Miscellaneous agents in our study included antianaemics, multivitamins, antacids, antimalarials, antidiabetics, antiemetics, laxatives, antidiarrhoea and anti-snake venoms. Multivitamins contain certain vitamins $A, E$ and certain metals such as zinc, copper, and manganese occurring in trace quantities have also been linked to important roles in wound healing (Guo and Dipietro, 2010). The biological properties of vitamin A include anti-oxidant activity, increased fibroblast proliferation, modulation of cellular differentiation and proliferation, increased collagen and hyaluronate synthesis, and decreased mediated extracellular matrix 
degradation. Vitamin E, an anti-oxidant, maintains and stabilizes cellular membrane integrity by providing protection against destruction by oxidation. Vitamin $E$ also has anti-inflammatory properties and has been suggested to have a role in decreasing excess scar formation in chronic wounds (Guo and Dipietro, 2010).

Antianaemics contain iron which is also important and its role is linked to the perfusion of tissues with blood carrying enough oxygen to wound sites. Deficiency in these metals can impair wounds healing by impairing collagen production and strength of the wound (Builders and Builders, 2016). Since the treatment of wounds was based on the patient as a whole and not the wound alone, as well as the needs of the individual therefore there was a significant association between the wound prescription and the gender of the patients.

Wound patients in this hospital setting were managed by arrays of analgesics because the patients experienced both nociceptive and neuropathic pains. Nociceptive and neuropathic pains can either be acute or chronic; however, neuropathic pains are the major contributors to most chronic pains. Nociceptive pains arise from damaged tissues and wounds such as compound fracture, burns, bruises, and inflammatory disorders are typically nociceptive (Builders and Builders 2016). Neuropathic pains are caused by either damage or dysfunction in the (peripheral and central) nervous system. The pains are often described by patients as burning, tingling, shooting, stinging, piercing, stabbing, etc, and can be managed pharmacologically with acetaminophen, non-steroidal anti-inflammatory drugs (NSAIDs) such as ibuprofen, ketoprofen, diclofenac and opioids which include pentazocine, morphine and tramadol (Choiniere et al., 1989).

The type and intensity of wound pain a patient experiences is influenced by many physical factors such as cause/site of the wound and since pain relief involves the treatment of the cause of pain as well as treatment of the pain itself as well as assessment of patient individually (Oladeinde et al., 2013); this therefore explains the significant association between the analgesic prescriptions and the gender of the patient (Builders and Bassi, 2017).

In this study, patients with assaults, road crashes, gunshots, bomb blasts, animal bites, burns, surgery, diseases, occupational, and domestic accidents accounted for more than half of the hospital stay with length of hospital stay of 1-7days, since length of hospital stay can be used as a surrogate in epidemiological studies to identify and characterize patients with severe injuries, therefore this result agree with other studies
(Ogendi and Ayisi, 2011).

Hospital length of stay was greater for patients with chronic wounds, these were the patients with problematic wounds frequently result in a loss of productivity; extended hospital stays of more than 30 days and increased expenditure (HSE, 2009). The aetiology of wounds, is an efficient predictor of hospital length of stay andmortality, therefore the cause of wound is associated with the length of stay in the hospital (Rowan et al., 2015).

\section{CONCLUSION}

Wounds cause pain, suffering, sepsis, infection, nausea, fatigue, depression, psychological disturbances, loss of function, loss of mobility and personal financial cost as well as amputation and even death. To improve the quality of life of wound patients' reliable epidemiological information on wound pattern is essential to health care providers to plan program for effective wound control and prevention.

\section{ACKNOWLEDGEMENT}

The authors appreciate the support and cooperation of all the staff of medical record department of Bingham University Teaching Hospital.

\section{REFERENCES}

Adigun IA, Rahman GA, Yusuf IF, Ofoegbu CKF (2010). The point prevalence and cost of wound management in a Nigerian teaching hospital. Nig. Med. J. 51:23-25.

Ameri M, Aghakhani K, Mehrpisheh S, Ameri E, Memarian A (2016).Epidemiological review of relation between gender and traumatic injuries in hospitals in Iran. Global J. Health Sci. 8: 15-19.

Bodeker G, Kronenberg F (2002). A public health agenda for traditional, complementary, and alternative medicine. Am. J. Pub. Health. 92: 1582-1591.

Brown A (2014). Strategies to reduce or eliminate wound pain. Nurs. Times. 110: 12-15.

Builders PF, Builders MI (2016). Wound Care: Traditional African Medicine Approach. Chapter contributed to the book topics on Worldwide Wound Healing - Innovation in natural and conventional methods, In Tech, Chapter 1, 126. DOI: $10.5772 / 62668$.

Builders MI, Akande P, Ramyil MS, Ogundeko TO (2014). Pattern of hospitalization in Bingham University Teaching Hospital. The Pharma Innov. J. 3: 11-19. 
068 J. Med. Med. Sci.

Builders MI, Bassi AM (2017).Evaluation of Analgesic Usage in Pain Management in Bingham University Teaching Hospital. Pediatri. Adolesc. Med. 2: 6-10.

Builders MI, Okonta JM, Aguwa CN (2011). Prescription patterns of analgesics in a community hospital in Nsukka. J. Pharm. Sci. Res. 3: 1593-1598.

Chandran PK, Kuttan R (2008). Effect of calendula officinalis flower extract on acute phase proteins, antioxidant defense mechanism and granuloma formation during thermal burns. J. Clin. Biochem. Nutr. 43:58-64.

Cheng K, Li J, Kong Q, Wang C, Ye N, Xia G (2015). Risk factors for surgical site infection in a teaching hospital: a prospective study of 1,138 patients. Patient Preference and Adherence. 9: 1171-1177.

Choiniere M, Melzack R, Rondeau J, Girard N, Paquin MJ (1989). The pain of burns: characteristics and correlates. J Trauma .29: 1531-1540.

Collier M (2001). A ten-point assessment plan for wound management. J. Comm. Nurs 16: 22-26.

Eming SA, Krieg T, Davidson JM (2007). Inflammation in wound repair: molecular and cellular mechanisms. J. Invest. Dermatol. 127:514-544.

Fillingim RB, King CD, Ribeiro-Dasilva MC, Williams BR, Riley JL (2009). Sex, Gender, and Pain: A Review of Recent Clinical and Experimental Findings.J Pain. 10: 447-485.

Foltran F, Avossa F, Fedeli U, Baldi I, Spolaore P, Gregori D (2013). Seasonal variations in injury rates in children: evidence from a 10-year study in the Veneto Region, Italy. Int J InjContrSafPromot. 20 :254-262.

Guo S, Dipietro LA (2010). Factors Affecting Wound Healing. J Dent Res 89: 219-229.

HSE (2009) National best practice and evidence based guidelines for wound management. Health Service Executive, Dublin.

Kumarasamyraja D, Jeganathan NS, Manavalan R (2012). Review on medicinal plants with potential wound healing activity. Int. J. Pharm. Sci. 4: 105-111.

Lakshmi PV, Tripathy JP, Tripathy N, Singh S, Bhatia D, Jagnoor J, Kumar R (2016). A pilot study of a hospitalbased injury surveillance system in a secondary level district hospital in India: lessons learnt and way ahead. Injury Epidemiol. 3:24.

Mohammed A, Adeshina GO, Ibrahim YK (2013). Retrospective incidence of wound infections and antibiotic sensitivity pattern: A study conducted at the Aminu Kano Teaching Hospital, Kano, Nigeria. Int. J. Med. Med. Sci. 5: 60-66.

Morrison A, Stone DH, Doraiswamy N, Ramsay L (1999). Injury surveillance in an accident and emergency department: a year in the life of CHIRPP. Arch. Dis. Child. 1999; 80:533539.
Nicks BA, Ayello EA, Woo K, Nitzki-George D, Sibbald RG (2010).Acute wound management: revisiting the approach to assessment, irrigation, and closure considerations. Int. J. Emerg. Med. 3:399-407.

Norman R, Matzopoulos R, Groenewald P, Bradshaw D (2006). The high burden of injuries in South Africa. Bull. World Health Org. www.who.int/bulletin/volumes/85/9/06037184/en.

Ogendi JO, Ayisi JG (2011). Causes of injuries resulting in a visit to the emergency department of a Provincial General Hospital, Nyanza, western Kenya. Afr. Health Sci. 2: 255261.

Oladeinde BH, Omoregie R, Olley M, Anunibe JA, Onifade AA (2013). A 5 - year surveillance of wound infections at a rural tertiary hospital in Nigeria. Afr. Health Sci. 13: 351355.

Onwuezobe IA, Offong EI, Moses AE (2016). Bacterial Profile and Antimicrobial Susceptibility Pattern of Nosocomial Wound Infection in a Teaching Hospital at Uyo, Akwa Ibom State, Nigeria. The Niger. Health J. 16: 1-10.

Pediani R (2001). What has pain relief to do with acute surgical wound healing?Worldwide wounds. http://www.worldwide wounds.com/2001/march/Pediani/backup.

Rowan MP, Cancio LC, Elster EA, Burmeister DM, Rose LF, Natesan S, Chan RK, Christy RJ, Chung KK (2015). Burn wound healing and treatment review and advancement. Critical care . 1-12.

Smith $P$ (2013). The relationship between age and work injury in British Columbia: Examining differences across time and nature of injury. J. Occupat. Health. 55: 98-107.

Taiwo OA, Cantley FA, Slade MD, Pollack KM, Vegso S, Fiellin MG, Cullen MR (2006).Sex differences in injury patterns among workers in heavy manufacturing. Am. J. Epidemiol. 69:161-166.

Thakur R, Jain N, Pathak R, Sandhu SS (2011). Practices in Wound Healing Studies of Plants. Evidence-Based Complementary and Alternative Medicine. 1-17. 